\title{
El nacional-populismo y sus consecuencias en el orden internacional
}

\section{Manuel Alejandro Rayran Cortés*}

\section{RESUMEN}

El nacional-populismo ha irrumpido el escenario internacional de manera sorpresiva. Sus representantes políticos han conquistado cargos de suma importancia, desde los cuales han tratado de modificar el actual orden mundial. Los detractores del populismo hallan su causa en los pensamientos malsanos de sus dirigentes, mientras que otros lo encuentran en los déficits de la democracia y los cambios estructurales de los asuntos económicos y sociales. Es así que este artículo busca explicar las causas del actual fenómeno y sus consecuencias en el orden internacional, estudiando el caso de Estados Unidos con el actual presidente Donald Trump.
Palabras clave: nacionalismo, populismo, democracia, orden internacional, Estados Unidos, Donald Trump.

\section{National-populism and its consequences in the international order}

\begin{abstract}
National-populism has emerged into the international scene in an unexpected way. Its political representatives have obtained important positions, from which they have tried to modify the current world order. The detractors of populism find their cause in the unhealthy thoughts of
\end{abstract}

\footnotetext{
* Magíster en ciencia política orientación en relaciones internacionales, con especialidad en diplomacia y resolución de conflictos, Universidad Católica de Lovaina. Docente de la Facultad de Finanzas, Gobierno y Relaciones Internacionales, Universidad Externado de Colombia, Bogotá (Colombia). [manuel.rayran@uexternado.edu.co].

Recibido: 31 de marzo de 2018 / Modificado: 23 de julio de 2018 / Aceptado: 23 de julio de 2018

Para citar este artículo:
}

Rayran Cortés, M. A. (2018). El nacional-populismo y sus consecuencias en el orden internacional. OASIS, 28, pp. 45-64. DOI: https://doi.org/10.18601/16577558.n28.04 
their leaders, while others find it in the deficits of democracy and structural changes in economic and social affairs. Thus, this article seeks to explain the causes of the current phenomenon and its consequences in the international order, studying the case of the United States with the current president Donald Trump.

Key words: Nationalism, populism, democracy, world order, United States, Donald Trump.

\section{INTRODUCCIÓN}

Durante los últimos años, el fenómeno nacional-populista ha reaparecido en el tablero del ajedrez político de los países tanto desarrollados como en vía de desarrollo. Esta manifestación política ha logrado cautivar los corazones de los votantes en las diferentes contiendas electorales, desplazando así poco a poco a los partidos tradicionales que han gobernado. Muestra de esto se evidencia con la elección presidencial de Donald Trump en los Estados Unidos o con el notable protagonismo de líderes populistas en Europa, como por ejemplo Boris Johnson y Nigel Farage, líderes del Brexit en Gran Bretaña, Geert Wilders en los Países Bajos, Marine Le Pen en Francia, el primer ministro de Hungría, Viktor Orbán, la vicepresidenta de Polonia, Beata Szydlo y la líder y parlamentaria del partido ultraderechista alemán, Alice Weidel.

Ante estas nuevas expresiones nacionalpopulistas presentadas en Estados Unidos y Europa surge la pregunta, ¿qué consecuencias traería para el orden internacional el resurgimiento del nacional-populismo? Para dar respuesta a este cuestionamiento, se utilizó una metodología inductiva para la cual se recopilaron en francés, inglés y español teorías e información de la situación política y económica actual. La hipótesis que se plantea a este cuestionamiento es que el nacional-populismo ha sido un catalizador de exigencias de las sociedades originadas por los cambios estructurales. Es así que, la agudización de las actuales alteraciones económicas y sociales debilita el actual multilateralismo y profundiza el declive relativo de los Estados Unidos. Para entender mejor el presente fenómeno se toma como caso de estudio Estados Unidos porque es el país que ha estructurado el orden internacional desde 1945 y actualmente tiene un presidente catalogado como populista.

Con el fin de desarrollar la hipótesis antes mencionada, en la primera parte se desarrollará la teoría de nación, nacionalismo y populismo, complementado por una breve descripción de los tres momentos en los que el nacional-populismo ha estado presente $\mathrm{y}$ las consecuencias que trajo este para el orden internacional. Posteriormente se estudiarán las causas del surgimiento del nacional-populismo en Estados Unidos y se determinará si Trump clasifica en la categoría de populista. Finalmente, se analizarán las consecuencias de este fenómeno en el actual orden internacional y se esgrimirán unas conclusiones preliminares.

\section{EL NACIONAL-POPULISMO: CATALIZADORES DE INCONFORMIDADES DE LA SOCIEDAD E INSULTOS EN LAS ACTUALES DEMOCRACIAS}

Para comprender mejor el nacionalismo y el populismo es necesario realizar un esbozo breve sobre la democracia debido a que estos 
dos conceptos nacen de esta estructura participativa y de organización social. De acuerdo con los filósofos griegos, la democracia es un régimen político por y para el pueblo, lo que presupone que el sistema democrático debe mantenerse a la altura de las demandas de este. Sin embargo, esta condición se ha incumplido desde los orígenes de la democracia griega hasta hoy, ya que en todas las sociedades se han estructurado bajo dos divisiones sociales -la élite y la multitud- y entre las cuales una somete a la otra. Por ejemplo, los atenienses designaron a los primeros como los algunos y a los segundos como numerosos (Delsol, 2016), para el pensamiento marxista los primeros son la burguesía mientras que los segundos son el proletariado. Si bien cada uno los cataloga a su manera, tanto la élite -algunos o burguesía-, como la multitud -numerosos o proletariado-, tienen características propias e innatas a cada una de ellas, por ejemplo, la multitud, por definición, son superiores en cantidad a la élite, pero inferiores en calidad.

Igualmente, los filósofos atenienses consideraban que la élite es la que, luego de analizar a la multitud, puede tomar las mejores decisiones para el bien común ya que tienen el conocimiento y la capacidad para encontrar la verdad, mientras que los segundos, debido a que no tienen educación, no pueden tomar decisiones importantes, por lo que los convierte en ilotas ${ }^{1}$ (Delsol, 2016). Es decir, la élite es la que puede, en últimas, diseñar y estructurar la sociedad y el bien común. Con base en lo anterior y en el marco de lo que Anthony Smith clasificó como teorías modernas-estructuralistas, la nación es considerada como una “(...) comunidad política, creada, mecánica, dividida y esencialmente construida por las élites" (Márquez, 2011). Así, pues, nación moderna, clasificación surgida a mediados el siglo XIX y establecida por el historiador Eric Hobsbawn, es

la comunidad de los ciudadanos de un Estado, viviendo bajo el mismo régimen o gobierno y teniendo una comunión de intereses; la colectividad de los habitantes de un territorio con tradiciones, aspiraciones e intereses comunes, y subordinados a un poder central que se encarga de mantener la unidad del grupo (Hobsbawn, 1991, pp. 23 y 24).

Por otra parte, así como la élite antes descrita es capaz de estructurar la sociedad, también puede fundar corrientes de pensamiento con el objetivo de mantenerse en el poder. Es así que el nacionalismo, de acuerdo con Paul Brass, es:

una ideología creada por élites que usan marcadores identitarios como la lengua y la raza para movilizar masas disponibles que han perdido sus referentes tradicionales como producto de la modernización. Esta movilización tiene como objetivo alcanzar o consolidar el poder de esas élites (Márquez, 2011, p. 584).

1 De acuerdo con los filósofos griegos, los ilotas eran aquellas personas que obedecían a las leyes e instituciones sin tener un conocimiento real del porqué de su aplicabilidad. Asimismo, eran personas que por su falta de educación no eran capaces de llegar a la verdad universal como tampoco identificar el bienestar común. De ahí que, su único apego era el cumplimiento de su propio deseo de manera inmediata y sin pensar las consecuencias que traerían sus actos a largo plazo (Delsol, 2016). 
Es necesario tener claro que esas corrientes de pensamiento también se refuerzan o se debilitan a través de los mecanismos establecidos por la democracia y de acuerdo con la realidad que vive la sociedad en su momento.

Habiendo explicado nación y nacionalismo ahora se profundizará sobre el populismo, el cual presenta problemas importantes desde su definición hasta su aplicación. El origen del rechazo al populismo y su mala imagen proviene de la discusión sobre la psicología de las masas, que, a través de la construcción de una matriz de características, organizó una perspectiva general sobre los fenómenos políticos categorizándolos como "aberrantes" y en el que incluyó el populismo (Laclau, 2005). Por esta razón, la literatura que aborda este tema se caracteriza por tener una ausencia conceptual, y para suplir este vacío recurre a la intuición, imaginarios y rasgos característicos. Esta carencia y ambigüedad ha permitido en la actualidad que el populismo se convierta en un insulto, asignándoselo a las personas que no comparten las ideas y políticas económicas y sociales del establecimiento, y vetando un debate trascendental sobre el bienestar de las sociedades (Delsol, 2016).

Con el fin de aclarar el populismo y entender cuándo este se convierte en un factor desestabilizador será necesario abordarlo desde una categoría de análisis político, es decir, como un producto de la misma democracia moderna y de la realidad social concreta del pueblo (Laclau, 2005). Para lograr esto será necesario aclarar algunas afirmaciones que desdibujan el concepto. Los detractores del populismo señalan comúnmente que sus líderes instrumentalizan el término "pueblo" para magrear a las multitudes y así conquistar sus votos. Sin embargo, esta afirmación desencadena dos problemas esenciales, por un lado, el "pueblo" lo asignan como un elemento ideológico cuando en realidad expresa, de manera concreta, la relación entre los agentes sociales de una democracia (Laclau, 2005) y, por el otro, la afirmación le da una connotación negativa a la búsqueda de votos, cuando por la misma definición de democracia, los candidatos a cargos de representación popular se deben al pueblo y a sus exigencias, introduciendo así su carácter de solidaridad entre la comunidad (Delsol, 2016).

Asimismo, los críticos del populismo afirman que el discurso de sus líderes es simplista y vago, pero esta ambigüedad no es porque los representantes sean ignorantes, sino por, como lo afirma Laclau en su libro La razón populista, la imprecisión de la acción política y la expansión de las demandas sociales. Con respecto a lo primero Laclau sostiene que las palabras tienen un poder significativo sobre las personas porque están unidas a las imágenes. No obstante, en algunos casos hay palabras que con el pasar del tiempo pierden su verdadero significado, pero tienen una fuerte influencia. Esto sucede cuando existe una inestabilidad entre el significado y el significante -palabra e imagen-y la palabra condensa en sí misma una pluralidad de significados como, por ejemplo, democracia, socialismo, igualdad, libertad (Laclau, 2005). Ahora bien, en referencia a las peticiones sociales, estas transitan a reclamos cuando son incumplidas o ignoradas, y en el momento en que se acumulan originan una articulación entre ellas creando así una frontera interna en la sociedad, "ellos" y "nosotros", y apareciendo la movilización política en su más 
alta expresión. Es así que, la agudización de las demandas sociales y el incumplimiento de estas por parte del régimen político terminan por convertirse en el principal suministro para el populismo.

Teniendo claro que el populismo es producto de la misma democracia, ahora es necesario plantear qué hace que el populismo se convierta en un factor perturbador. El componente que le concede la mala imagen al populismo es la demagogia que utilizan sus líderes, los cuales recogen los caprichos de la multitud, les dicen lo que quieren escuchar, halagan los deseos primarios de corto plazo de los numerosos y secuestran el poder legítimo de la razón con sus argumentos malsanos (Delsol, 2016). Esta demagogia se convierte así en un factor distractor de la multitud y de la realidad misma, pues los populistas realizan el ejercicio político no para solucionar los problemas del pueblo sino para conquistar el poder para su beneficio propio.

Luego de la explicación teórica, en los siguientes párrafos se describirán brevemente los momentos históricos cuando el nacionalismo canalizó las disconformidades de la sociedad y sus consecuencias en el orden internacional. De acuerdo con Hobsbawm, el nacionalismo estuvo presente en tres momentos claves de cambio de la sociedad, el primero se presentó en el siglo xviII y lo catalogó como el nacionalismo gubernamental, el segundo fue el nacionalismo entre el período de 1880 a 1914, y el tercero entre 1918 y 1950 (Márquez, 2011).

El primer nacionalismo surge en el siglo xviII con la Ilustración, la cual fue alimentada intelectualmente por John Locke con su pensamiento clásico del liberalismo, Thomas
Hobbes con la creación del Leviatán y JeanJacques Rousseau con el contrato social (Sepúlveda, 1996). Estos pensadores justificaron la creación del Estado (Kissinger, 2016) y fundamentaron intelectualmente el principio de soberanía nacional, entendido como una consecuencia del contrato social entre la sociedad civil y el Estado. Este nacionalismo logró superar el localismo feudal y eliminar de la vida política la idea que los reyes, por ley divina, tenían el derecho de gobernar (Sepúlveda, 1996). Este primer nacionalismo tuvo consecuencias en el orden internacional, pues reforzó los tratados de Westfalia en 1648, poniendo al Estado como actor principal del sistema internacional.

El segundo nacionalismo tuvo como principal reivindicación el derecho a la autodeterminación de las naciones. Estas reclamaciones de los pueblos coloniales surgieron por las prácticas imperialistas de los centros de poder europeos, la competencia económica agresiva y la guerra imperialista materializada con la primera guerra mundial. Luego que las potencias del viejo continente, para ese momento Gran Bretaña, Francia, Alemania, Rusia y Austria-Hungría, hubiesen resuelto su acomodamiento territorial interno, surgió el espíritu colonial cuyo objetivo era la conquista de suelos en ultramar para competir con Gran Bretaña, mejorar su posición territorial dentro de Europa y mantener y defender la herencia de hegemonía, caracterizada por la conquista de tierras con recursos que le permitieran al poder central mantener su estatus de potencia (Granados, 2010). Este proceso imperial toma fuerza con la Conferencia de Berlín de 1885, en la que se vinculan las élites políticas, empresarios, 
comerciantes y banqueros para exportar hacia las colonias los factores de producción que habían desarrollado los mercados internos de las potencias europeas. Esta proyección del capital en otros territorios no se originó con la intención de desarrollar las periferias, por el contrario, fue una opción para resolver el estancamiento del sector financiero y permitirles a estos países una mejor acumulación y especulación del capital.

Sin embargo, esta inyección de capital en otros países entra en crisis en 1905 debido a la excesiva concentración de la riqueza, la asfixia de la industria y el agro, y el alto endeudamiento público, desatando manifestaciones de los trabajadores y campesinos contra el modelo económico y pidiendo cambio de gobierno. Esta situación también representó transformaciones relevantes en el orden internacional, pues se desató la primera guerra mundial y despedazó los imperios alemán, austro-húngaro, otomano y el ruso zarista, desarrollándose en este último la revolución bolchevique liderada por Vladimir Ilich Lenin, quien inició la construcción de Unión de Repúblicas Socialistas Soviéticas (URSS), actor político relevante en el siglo xx.

La tercera ola de nacionalismo, según Hobsbawm, emerge entre los años 1918 a 1950 caracterizado por la descolonización de territorios africanos y asiáticos por parte de los Estados europeos. Esta independencia se da gracias a dos factores: uno nacional, con el surgimiento de líderes nacionalistas que reclamaban una independencia real de los centros de poder, y otra internacional, con una crítica anticolonial mundial instalada después de la primera guerra mundial en diferentes regiones del mundo, que progresivamente tomó fuerza y luego fue respaldada por la Organización de las Naciones Unidas (ONU) con la Resolución 1514 de 1960, y la solidaridad de los nuevos países independientes con la Conferencia Afroasiática de Bandung (Indonesia) celebrada del 18 al 24 de abril de 1955, con la que declaran su neutralidad en la guerra fría y remarcan su oposición al colonialismo y a favor de la independencia de los pueblos sometidos por las potencias imperialistas.

Esta lucha política de los líderes nacionalistas africanos y asiáticos por la independencia tuvo eco en los pueblos del mundo por un discurso potente, el cual integraba los siguientes elementos: 1. La contradicción de los países europeos al reivindicar su independencia y su plena soberanía política y económica, pero la negación de estas a sus colonias. 2. La difusión de las ideas democráticas y el cambio de mentalidad que nació en el momento en que los nativos de las colonias se educaron en las universidades europeas. 3. La recuperación de la identidad nacional y valores culturales. 4. El odio racial a los blancos europeos por su implementación del capitalismo y el imperialismo (Muñoz, 2011). Es así que esta ola nacionalista también tuvo impactos en el sistema internacional, pues con la independencia de las colonias en nuevos países le otorgó credibilidad a la ONU, incrementó el número de naciones en el sistema internacional y concedió voz y voto a pueblos que años atrás habían sido completamente ignorados por los centros de poder europeo.

Sin embargo, el fenómeno nacionalista no desaparece con la descolonización en Asia y África, por el contrario, al terminar el siglo xx, 
se presentó de nuevo un oleaje de nacionalismo en Europa central y del este. Durante los años de la guerra fría, los nacionalismos aparentaron desaparecer en esta región del mundo por la hegemonía de la URSs sobre estos países, pero con la caída de este bloque político en 1989, reapareció este fenómeno caracterizado por las reivindicaciones de las minorías étnicas que reclamaban nuevos Estados. Este cambio estructural del sistema internacional y la reaparición del fenómeno nacionalista provocó conflictos sangrientos como, por ejemplo, el de la disolución de la República Federativa Socialista de Yugoslavia, fragmentándola en seis Estados diferentes reconocidos internacionalmente: Bosnia y Herzegovina, Croacia, Eslovenia, Macedonia, Montenegro y Serbia. Si bien Kosovo es un Estado, hay que aclarar que es producto de la desintegración de Serbia $\mathrm{y}$ aún no ha sido reconocido plenamente por todos los países.

Ahora bien, en el siglo xxI el fenómeno nacional-populista brota nuevamente con el objetivo de romper el pensamiento económico hegemónico que se estableció desde que Estados Unidos pasó a ser una hiperpotencia. La supremacía del gigante del norte en el mundo le ha servido para expandir, de manera dogmática, su modelo económico neoliberal, garantizándole así la reproducción del capital del sistema financiero en detrimento de la clase trabajadora. Esta situación ha alimentado el rechazo de la población a esa doctrina financiera y elevado su rabia hacia los políticos tradicionales ya que se siente traicionada. Con base en la anterior situación, la población está dispuesta a escuchar otro tipo de ideas e incluso radicales.
No obstante, los dirigentes populistas, como Donald Trump, han demostrado que tampoco actúan en beneficio de las mayorías, sino que canalizan esta rabia con discursos demagógicos para obtener sus votos, pero luego en el poder aplican políticas que benefician a los dueños de las grandes corporaciones financieras y no a sus electores.

Para evidenciar con mayor claridad lo anterior, en el siguiente subtítulo se revisarán las causas por las que el populismo en Estados Unidos tuvo éxito con el presidente Donald Trump.

\section{LOS CAMBIOS ECONÓMICOS Y SOCIALES DEL SISTEMA INTERNACIONAL, CASO ESTADOS UNIDOS}

El surgimiento del actual fenómeno nacionalpopulista tiene raíces en los cambios estructurales tanto económicos como sociales que se han acumulado desde 1970. La crisis financiera de 2008, originada en Wall Street, además de perjudicar a todas las economías del mundo, golpear las condiciones de los menos favorecidos, a los trabajadores y la clase media en general, también mostró problemas constitutivos en el actual sistema económico internacional, las malas prácticas del sector financiero y de los órganos de control.

Estas deficiencias estructurales, que llevaron a la crisis financiera de 2008, se evidencian con el estancamiento de la economía real, específicamente la de los Estados Unidos, que de acuerdo con Paul Baran, Paul Sweezy y Harry Magdoff, durante los años sesenta y noventa produjeron el anquilosamiento de la economía monopolista capitalista que era constante en el 
tiempo, su prosperidad solo se podía atribuir a factores históricos temporales ${ }^{2}$ y la respuesta a esta paralización económica era la explosión financiera (Bellamy \& Magdoff, 2009). Asimismo, si bien los economistas de la corriente dominante afirman que el crecimiento rápido es una característica intrínseca al capitalismo y que sus recesiones son momentáneas, cíclicas y autocorregibles; autores como Sweezy y Magdoff consideran que la ralentización de la economía capitalista es el camino normal de las economías maduras y no el crecimiento rápido, de ahí que las recesiones no sean vistas como algo transitorio, sino una limitación a largo plazo sobre la acumulación del capital.

El estancamiento creciente de la economía real, antes mencionado, se evidencia con la Tabla 1 que muestra cómo el crecimiento del Producto Interno Bruto (PIB) real de los Estados Unidos entre 1930 y 2007 se reduce. Los datos de la Tabla demuestran que para los años treinta la Gran Depresión afectó, de manera considerable, la economía estadounidense, seguido del extraordinario crecimiento de los años cuarenta que se atribuyen al impacto de la segunda guerra mundial y la "era dorada" entre los años cincuenta y setenta, en la que la economía creció en tiempo de paz. Sin embargo, es a partir de 1980 que las tasas de crecimiento se reducen y la baja expansión de la economía se convierte en tendencia.

\section{Tabla 1}

Crecimiento del PIB real (1930-2007)

\begin{tabular}{|c|c|}
\hline & Porcentaje medio anual \\
\hline $1930-1939$ & 1,3 \\
\hline $1940-1949$ & 5,9 \\
\hline $1950-1959$ & 4,1 \\
\hline $1960-1969$ & 4,4 \\
\hline $1970-1979$ & 3,3 \\
\hline $1980-1989$ & 3,1 \\
\hline $1990-1999$ & 3,1 \\
\hline $2000-2007$ & 2,6 \\
\hline
\end{tabular}

Fuente: Bellamy, J. \& Magdoff, F. (2009, p. 185).

Por otro lado, el estancamiento de la economía estadounidense y la explosión de las finanzas incidieron en el deterioro de las condiciones laborales y los salarios de los estadounidenses. A partir de los años setenta, a causa de la ralentización económica, el capital, con el fin de aumentar sus beneficios, inició una lucha contra los trabajadores presionando a las administraciones demócratas y republicanas para reducir los costes laborales, lo que condujo a

2 Acorde con estos teóricos la prosperidad económica solo se podría atribuir a los siguientes factores históricos: “1) La acumulación de ahorros por parte del consumidor durante la guerra; 2) una segunda gran oleada de automovilización de los EE.UU. (incluida la expansión de las industrias del vidrio, el acero y el caucho, la construcción de un sistema interestatal de autopistas y el desarrollo de las zonas residenciales); 3) la reconstrucción de las economías europea y japonesa devastadas por la guerra; 4) la carrera armamentista de la guerra fría; 5) el crecimiento del esfuerzo de ventas marcado por el ascenso de Madison Avenue; 6) la expansión de las finanzas, seguros y propiedad inmobiliaria; y 7) la preeminencia del dólar como moneda hegemónica” (Bellamy y Magdoff, 2009, p. 183). 
un aumento en las desigualdades y desmejoró la redistribución de la riqueza (Bellamy \& Magdoff, 2009). El Gráfico 1 refleja la participación de los salarios en el pıв entre los años setenta y dos mil cinco, lo que significa que "en EE.Uu. los salarios reales de los trabajadores privados no agricultores (en dólares de 1982) alcanzaron su punto máximo en 1972 con 8,99 dólares por hora y en 2006 ya habían caído a 8,24 dólares (equivalentes a la tasa de salario real por hora de 1967)" (Bellamy \& Magdoff, 2009, p. 185).

Gráfica 1

Gastos de sueldos y salarios en porcentaje del PIB

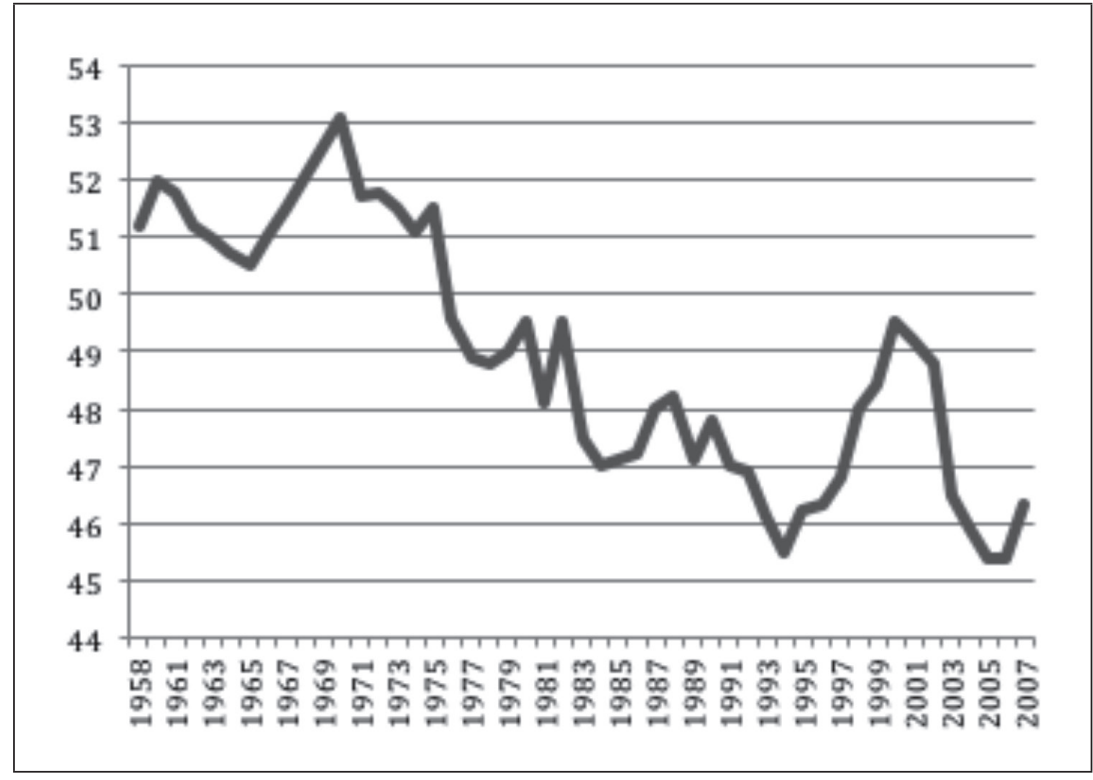

Fuente: Bellamy, J. \& Magdoff, F. (2009, p. 186).

Ante el estancamiento de la economía real y la caída de los salarios de los trabajadores, el capital decidió apalancar su salida al problema expandiendo la deuda tanto en las empresas no financieras como financieras, en los hogares y en todos los niveles del gobierno, obteniendo así beneficios especulativos y una explosión financiera. En la Tabla 2 y la Gráfica 2, se puede evidenciar, de manera clara, como a partir de 1970 hasta el 2007, un año antes de la crisis financiera, las empresas, el sector financiero, los hogares y el gobierno se endeudaron de manera considerable aun con una economía real que no tenía la capacidad para respaldar tal endeudamiento. 
Tabla 2

Deuda nacional y PIB (en billones de dólares) endeudamiento por sector

\begin{tabular}{|c|c|c|c|c|c|c|}
\hline & PIB & Deuda total & Hogares & $\begin{array}{c}\text { Empresas } \\
\text { financieras }\end{array}$ & $\begin{array}{c}\text { Empresas no } \\
\text { financieras }\end{array}$ & $\begin{array}{c}\text { Gobierno (local, } \\
\text { estatal y federal) }\end{array}$ \\
\hline 1970 & 1,0 & 1,5 & 0,5 & 0,1 & 0,5 & 0,4 \\
\hline 1980 & 2,7 & 4,5 & 1,4 & 0,6 & 1,5 & 1,1 \\
\hline 1990 & 5,8 & 13,5 & 3,6 & 2,6 & 3,7 & 3,5 \\
\hline 2000 & 9,8 & 26,5 & 7,0 & 8,1 & 6,6 & 4,6 \\
\hline 2007 & 13,8 & 47,7 & 13,8 & 16,0 & 10,6 & 7,3 \\
\hline
\end{tabular}

Fuente: Bellamy, J. \& Magdoff, F. (2009, p. 174).

Gráfica 2

Endeudamiento privado en porcentaje del PIB

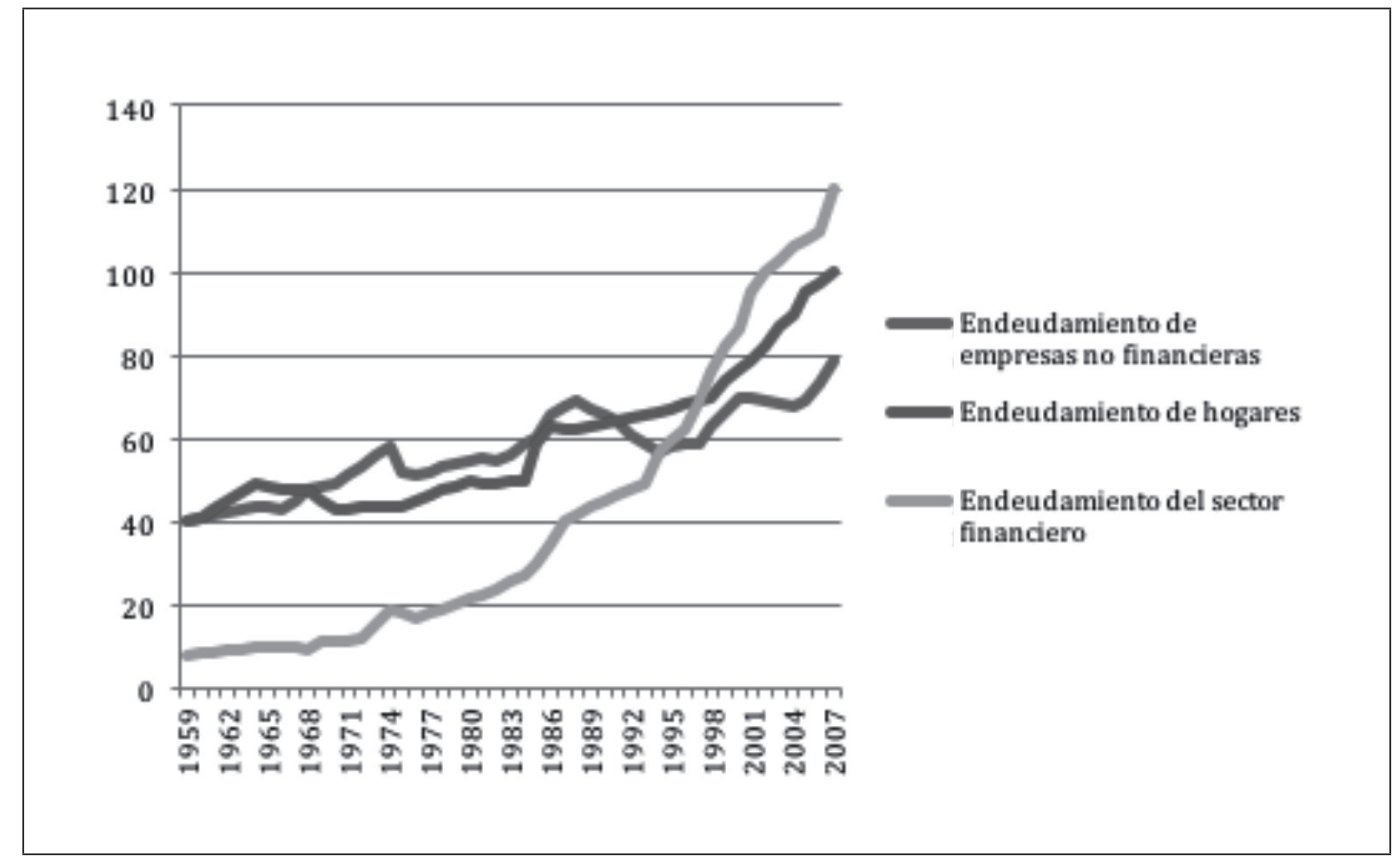

Fuente: Bellamy, J. \& Magdoff, F. (2009, p. 175). 
La situación económica antes descrita originó que la distribución de la riqueza inequitativa en los Estados Unidos aumentara, permitiendo así que las personas ricas fueran más ricas y los pobres más pobres. Esto se evidencia con el coeficiente Gini, que para 2017 fue el más alto de los países desarrollados que pertenecen a la Organización de Cooperación y el Desarrollo Económico (Ocde) con un 0,48 (Statista, 2016). Asimismo, la desigualdad económica también se refleja con que el ingreso medio del $10 \%$ de los más ricos es nueve veces más elevado que el ingreso medio del 90\% de los otros estadounidenses, y que el $47 \%$ de los más pobres no tengan ninguna riqueza debido a que sus deudas son más altas que sus ingresos y propiedades sumadas (Landes, 2016).

A este problema económico y de salarios se le agrega que el sistema electoral está dominado por el dinero de las grandes corporaciones privadas, la influencia de los lobbies y su distanciamiento cada vez más grande con las demandas de los electores estadounidenses. Las inversiones de dineros de estas compañías en los candidatos presidenciales no es algo nuevo, pues desde las administraciones de Theodore Roosevelt (1901-1909) y de William Howard Taft (1909-1913), evidenciaron este fenómeno y por ello el Congreso adoptó algunas leyes para regular el financiamiento de las campañas con el fin de salvaguardar la democracia. Es así que, para 1907 fue aplicada la Ley Tillman que prohibía expresamente las donaciones directas de compañías a las candidaturas, y para 1947 se sancionó la Ley Taft-Harley que restringe la inversión en los sindicatos. Sin embargo, unos años más tarde se crearon los Comités de Acción Política (Political Action Committee), conocidos como PAC permitiéndole a los sindicatos elevar los fondos de manera considerable y así poderlos transferir luego a los candidatos de manera legal.

A la creación de los PAC se le suma la Ley Campaña de Elecciones Federales (Federal Election Campaign Act) Feca por sus iniciales en inglés, enmendada en 1974, la cual estableció los montos máximos que podían transferir los particulares y empresas, como también sobre la transparencia de las donaciones; pero el problema radica en que la Feca consagró a los PAC como los medios para recolectar los fondos, extendiéndola a las grandes corporaciones. De igual forma, esta Ley omite el financiamiento de actividades que refuerzan a los partidos políticos, también conocido en Estados Unidos como los "soft money", cuyo objetivo no es financiar directamente al candidato sino a los partidos políticos, y cuyo recurso se termina invirtiendo, en la mayoría de las ocasiones, en piezas publicitarias que critican al responsable político de alguna medida tomada y sensibilizan al televidente sobre alguna problemática sin mencionar a un candidato en especial por quien votar.

Es así que, a raíz de estas leyes, las candidaturas a la Presidencia y al Senado cada vez son más costosas, teniendo que buscar exorbitantes sumas de dinero para conquistar algún cargo de representación popular porque los aportes de los votantes no son suficientes. Un ejemplo claro de la magnitud de las inversiones realizadas por las corporaciones privadas a los candidatos se divisó en la elección presidencial de 2016 entre los candidatos Hillary Clinton del Partido Demócrata y Donald Trump del Partido Republicano. Acorde con el Centro por una Política 
Responsable, Open Secrets, Robert Mercer, de Renaissance Technologies, transfirió 16,7 millones de dólares a los republicanos; Thomas Steyer, de Next Generation y George Soros, de Soros Fund Management, donaron 13 y 8 millones de dólares a los demócratas respectivamente (Landes, 2016). De ahí que se entienda el porqué las políticas implementadas por el presidente electo están direccionadas a favorecer a esos sectores económicos y no a sus electores.

Es así que la suma de los anteriores elementos contribuyó para que los electores estadounidenses elevaran sus niveles de inconformidad hacia los políticos tradicionales y buscaran candidatos que prometieran modificar radicalmente esa situación. Este contexto lo entendió a cabalidad el multimillonario Donald Trump, quien, si bien no representa los intereses reales de los trabajadores y la clase media del país, ya que él pertenece a ese selecto grupo de ricos norteamericanos que se han beneficiado con la reducción de los costes laborales y la desregulación financiera, logró convencer a los electores que él sería la persona indicada para mejorar las condiciones de vida del pueblo estadounidense. Lo anterior lo conquistó gracias a su discurso nacionalpopulista caracterizado por tener soluciones simples a problemas complejos, reviviendo el sentimiento nacionalista con el rechazo a las personas de otras culturas, colores de piel y religión, prometiendo combatir las élites del establecimiento, juramentando retornar a Estados Unidos a los valores tradicionales de su sociedad y reduciendo los compromisos políticos y económicos que Washington ha adquirido con el mundo desde 1945, haciéndoles pagar a sus aliados los costos en que ha incurrido el gigante del norte por mantener el actual orden internacional.

Esta última promesa, caracterizada por hacer política interna con decisiones exteriores, es la que más preocupa a la diplomacia internacional, pues por primera vez, desde la segunda guerra mundial, un presidente de los Estados Unidos manifiesta explícitamente que cesará de buscar los intereses de ese país por medio del multilateralismo y lo reemplazará por mecanismos unilaterales y directos.

Con base en lo anterior, en los siguientes párrafos se estudiarán las consecuencias que traería el aislamiento de los Estados Unidos para el orden internacional, postura política que es alimentada por el discurso nacionalpopulista.

\section{CONSECUENCIAS DEL NACIONAL- POPULISMO EN EL SISTEMA INTERNACIONAL}

Desde que Estados Unidos asumió su rol de potencia mundial hasta el día de hoy ha afrontado distintas situaciones adversas a su liderazgo, por las cuales algunos analistas han sentenciado su descenso total en el escenario internacional. Sin embargo, si bien su declive no es completo, sí se puede afirmar que es relativo y se ha profundizado con su situación económica desfavorable por la crisis financiera de 2008 y con el arribo a la presidencia de Donald Trump. De manera que el actual fenómeno del nacional-populismo sea el resultado de ese declive que los Estados Unidos ha moldeado desde hace años con sus diferentes crisis económicas, políticas y sociales.

Como consecuencia del declive relativo de los Estados Unidos y su materialización con 
el nacional-populismo podrían identificarse cinco consecuencias al multilateralismo actual: cambios en las pautas de interacción o procesos en el actual orden internacional, afectación a la estructura política de su principal aliado la Unión Europa, el establecimiento de una agenda internacional poco clara para afrontar temas geopolíticos en la regiones, un auge en la toma de decisiones unilaterales que afectarán los acuerdos económicos y políticos ya establecidos, y el debilitamiento del orden mundial liberal.

Con respecto a la primera consecuencia, conforme al teórico Robert Gilpin, en su obra War and Change in World Politics, existen tres posibles cambios en la estructura de poder en el sistema internacional. El primero son los "cambios de sistema”, los cuales ocurren cuando existen modificaciones esenciales en el carácter internacional, por ejemplo, que la naturaleza de los principales actores del sistema se transforme, en otras palabras, que el Estado-nación sea reemplazado por agrupaciones regionales $\mathrm{u}$ otro actor. El segundo son los "cambios estructurales" que están motivados por variaciones en la distribución de poder entre las unidades del sistema y se dan dentro del mismo. Estas modificaciones estructurales tienen dos variaciones: una con consecuencias profundas que logran transformar las configuraciones básicas de poder, por ejemplo, la desaparición de la URSs, y otras cuyas secuelas son simples y sus variaciones en la distribución de poder son menores. Finalmente, están los "cambios en las pautas de interacción o procesos entre los actores internacionales", los cuales se entienden como modificaciones en la dinámica de las relaciones internacionales dentro del sistema de Estados (Sodupe, 2002).
Ahora bien, de acuerdo con esta clasificación de Gilpin, el actual nacional-populismo y sus consecuencias hasta el momento se podrían catalogar en la tercera opción, pues si bien este fenómeno ha tomado fuerza en Estados Unidos, en algunos países de Europa y Asia no tienen la capacidad suficiente para realizar cambios estructurales dentro del sistema, sumado a que los líderes populistas no buscan desafiar el liderazgo de los Estados Unidos sino tener una mayor capacidad de negociación con el fin de incrementar sus beneficios, y las instituciones políticas de la mayoría de países donde se presenta este fenómeno están consolidadas. De ahí que se busque simplemente modificar algunos criterios en la interacción entre los Estados.

La segunda consecuencia del actual nacional-populismo es la afectación a la estructura política de la Unión Europea, principal aliado de los Estados Unidos. Esta organización supranacional también fue golpeada por la crisis financiera de 2008 y las políticas económicas aplicadas por el Banco Central Europeo para remediar ese traumatismo financiero no han favorecido por igual a todos los países europeos. Aquella situación animó a que los ciudadanos del viejo continente apoyaran a líderes de partidos de extrema derecha e izquierda, que con sus discursos nacional-populistas han conquistado escaños en los parlamentos nacionales y ganado más voz en las instituciones europeas. Es así que, por ejemplo, acorde con el último estudio del Centro de Información de Política Europea (European Policy Information Center), Epicenter por sus iniciales en inglés, que explora el crecimiento del populismo autoritario en Europa a través del análisis de 
datos de las elecciones desde 1980 hasta 2017, se encuentra que los movimientos y partidos nacional-populistas, tanto de derecha como de izquierda, han recibido mayor apoyo por la ciudadanía de sus países. De las 7.843 curules, que fueron el total de las sillas parlamentarias a conquistar durante las últimas elecciones de los treinta y tres países europeos analizados, 1.372, es decir el 17,5\%, han sido conquistadas por estos partidos, logrando así obtener 55.8 millones de votos.

Hasta el momento, el golpe más contundente que ha proporcionado el nacionalpopulismo en Europa es el referendo del Brexit, con el cual Reino Unido decidió retirarse de la Unión Europea ya que según sus promotores esta institución supranacional transfería menos dinero de lo que este le aportaba y, por tal razón, sustrayéndose de ella el país recobraría la autonomía económica perdida. Esta situación tuvo dos consecuencias dentro de Europa. La primera secuela fue el ánimo que le transfirió a líderes populistas de otros países para que propusieran referendos, pues en ese momento se consideraban la mejor solución y una opción realizable. Este primer efecto se materializó con las propuestas del Grexit en Grecia, Nexit en Holanda y Frexit en Francia, pero que no obtuvieron un respaldo ya que no consiguieron el suficiente apoyo de los ciudadanos. La segunda secuela del Brexit fue el fraccionamiento político entre las potencias europeas. A causa de la decisión a favor del Brexit, David Cameron renunció a su cargo de primer ministro, reemplazándolo la conservadora Theresa May, quien inmediatamente tuvo afinidad política con el presidente de los Estados Unidos, Donald Trump. Este acerca- miento entre los dos políticos se concretó con que May fuera la primera líder extranjera en reunirse con el recién investido presidente de Estados Unidos y quien este último la llamó "mi Maggie" haciendo referencia a la Dama de Hierro (Margaret Thatcher).

Con esta reunión, el presidente Trump buscaba que Estados Unidos junto con Gran Bretaña, volvieran a liderar el mundo, como sucedió durante la segunda guerra mundial, y alejar a ese país de Alemania y Francia, fracturando así internamente a la Unión Europea. Lo anterior obligó a que la canciller Ángela Merkel de Alemania y el nuevo presidente de Francia, Emmanuel Macron, se organizaran y redistribuyeran tareas al interior de la institución supranacional ante este nuevo escenario internacional. Merkel, por su lado, asumió el papel de líder de la Unión Europea transmitiendo una actitud de unidad entre los países europeos para afrontar el nacional-populismo, pero a su vez de mano dura en la negociación con el Reino Unido para su retiro de la organización, demostrándole así a los líderes nacional-populistas que apartarse de la organización supranacional trae más consecuencias negativas que positivas. Por su parte, Macron se encargó de mantener lazos de comunicación y acercamiento con Trump para identificar sus estrategias y objetivos, concretándose con la invitación del presidente galo al mandatario estadounidense al desfile del 14 de julio en los Campos Elíseos en conmemoración al primer centenario de la entrada de Estados Unidos a la primera guerra mundial.

La tercera consecuencia es el establecimiento de una agenda internacional poco clara para afrontar temas geopolíticos en Europa, 
Asia y Medio Oriente. El presidente estadounidense, Donald Trump, durante campaña y desde el primer día en oficio, ha manifestado no estar de acuerdo con los compromisos multilaterales adquiridos, pues según el mandatario, estos perjudican los intereses de su país. Lo anterior se evidencia con la actitud del republicano Trump con los países miembros de la Organización del Tratado del Atlántico Norte (Otan), pues los amenazó con desfinanciar esta estructura y no respaldar a sus aliados europeos ante un ataque de Rusia hasta que estos paguen el dos por ciento de su PIB a la defensa de la institución, deuda que según el republicano es enorme. Esta postura política transmite inseguridad y poca claridad hacia las nuevas dinámicas en Europa y su vecino Moscú.

Con lo que respecta a la estabilidad en Asia, el mandatario estadounidense mantuvo una actitud hostil hacia el líder de Corea del Norte, Kim Jong-un, por la adquisición de armas nucleares, abriendo la posibilidad de una confrontación armada directa y de alto riesgo si es que el norcoreano no desiste de este armamento. No obstante, esta actitud ha cambiado por una más negociadora, sin incluir a sus aliados occidentales, evidenciándose en la reunión de Trump con el líder norcoreano el 11 de junio de 2018. En Medio Oriente su postura también ha sido adversa, pues con el bombardeo a la base aérea de Al Shayrat en Siria demostró que está dispuesto a tomar medidas unilaterales y sin consultar a la comunidad internacional, postura que no sorprende de Estados Unidos, pues con ese mismo comportamiento en 2003 inició una guerra contra Iraq sin justificación alguna.

La cuarta consecuencia del fenómeno nacional-populista de Trump es el auge en la toma de decisiones unilaterales que afectan los acuerdos económicos y políticos establecidos. Esta secuela ha sido evidente con el retiro de los Estados Unidos del Acuerdo Transpacífico de Cooperación Económica (TPP), con el cual el ex presidente Barack Obama (2009-2017) buscaba crear el bloque económico más grande del mundo para enfrentar a China en ese campo, aumentar la presencia de los Estados Unidos en las zonas económicas más dinámicas del mundo y ganar terreno en Asia. Si bien abandonar este acuerdo fue un acto sencillo de realizar debido a que aún necesitaba la aprobación del Senado, sí fue un símbolo importante para el mundo, pues con este abandono demostraba que cumpliría lo que había prometido en campaña, y que haría lo que fuere necesario para que los tratados económicos beneficien los intereses de los Estados Unidos.

Asimismo, estas decisiones unilaterales también se evidencian con el retiro de Estados Unidos del Acuerdo de París, cuyo objetivo es reducir las emisiones de carbono y evitar que la temperatura media global del planeta supere los $2^{\circ} \mathrm{C}$. Si bien no es de extrañar que Washington se retire o no ratifique acuerdos que benefician a la humanidad, lo que sorprende de su salida es que Donald Trump iniciara una campaña de desprestigio contra las pruebas científicas que demuestran que el calentamiento global es consecuencia de la acción humana y que el discurso ambientalista y ese acuerdo ambiental es un pacto injusto y peligroso para los intereses de Estados Unidos, pues impide la expansión industrial de su país y solo ofrece ventajas competitivas para China e India.

Esta consecuencia también se evidencia con la solicitud de reforma del Tratado de Li- 
bre Comercio de América del Norte (TLCAN). Acorde con Trump el trcan es causante del déficit comercial que tiene su país con México y Canadá, así como también acusa al país centroamericano de ser el causante de la pérdida de empleos en Estados Unidos. Por esta razón, el presidente republicano ha despotricado del TLCAN mientras que en las rondas de negociación ha buscado lograr concesiones en temas como reglas de origen, aumentar el porcentaje de requisitos para considerar un producto de origen y ha tratado de poner fin al sistema de arbitraje independiente.

El último ejemplo de esta cuarta consecuencia es la decisión unilateral del presidente Donald Trump de trasladar la embajada de los Estados Unidos a Jerusalén, reconociendo esta ciudad como capital de Israel. Esta resolución fractura la estabilidad que se había mantenido con el tiempo y acrecienta la incertidumbre en Medio Oriente. Washington tradicionalmente jugaba un rol de mediador en este conflicto e impulsaba la propuesta de crear dos Estados para mantener la estabilidad regional. En concordancia con esta lógica, si bien en 1995 el Congreso estadounidense decidió mudar la delegación diplomática a Jerusalén, los mandatarios tanto republicanos como demócratas postergaban ese cambio por seis meses justificándolo por temas de seguridad nacional. Sin embargo, con la decisión de Trump el juego político en la región cambió, pues asume una posición clara a favor de Israel y quiebra su posición de juez en ese conflicto. Más aún, esta decisión generó una serie de manifestaciones en contra como, por ejemplo, que Irán alzara su voz pidiendo a los países de la región romper relaciones con Israel, Turquía sentenció esa resolución como algo catastrófico y los grupos armados en la región amenazaron con tomar acciones violentas contra el pueblo israelí y el cuerpo diplomático estadounidense. A esta decisión unilateral, que de por sí ya es polémica, se agrega la actitud hostil de los Estados Unidos al amenazar con reducir el apoyo financiero a los países que apoyaran la resolución no vinculante de la Asamblea General de las Naciones Unidas que condenaba esa decisión.

La quinta consecuencia del actual fenómeno nacional-populista es el debilitamiento del orden mundial liberal. Después de la segunda guerra mundial, los Estados Unidos junto con Gran Bretaña y otras potencias establecieron un orden mundial liberal, caracterizado por un régimen de derecho, el respeto a la soberanía, la autonomía de los pueblos y la integridad territorial de los países. Todos estos ideales se mantuvieron porque Estados Unidos, como poder duro del sistema internacional, creó instituciones internacionales que le permitieron mantenerse como líder mundial y distribuyó beneficios a sus aliados para sostener tal orden, permitiéndoles así a las potencias preservar su estatus dentro de la estructura.

Sin embargo, este modelo se ha debilitado por las malas decisiones que los Estados Unidos ha tomado desde la caída de la URSs y se ha profundizado con el actual presidente Donald Trump, quien por sus acciones e intimidaciones ha logrado que varias naciones no le tengan la suficiente confianza para tratar de manera correcta los asuntos internacionales. Para evidenciar esta 
desconfianza entre los aliados tradicionales de Occidente, la ilustración uno constata que en los países tradicionalmente aliados de los Estados Unidos (América Latina y Europa) menos del veinte por ciento de su población confían en el mandatario estadounidense, mientras que más del cincuenta por ciento del pueblo ruso, israelí, nigeriano y vietnamita sí. Es así que el nacional-populismo del presidente Trump demuestra que afecta tanto al orden liberal, cuando el mandatario estadounidense decide tomar decisiones económicas y militares unilateralmente y excede los parámetros legales internacionales, como también profundiza el declive relativo de los Estados Unidos, permitiéndole a China, su principal oponente en el orden internacional, afianzarse más ya que el gigante asiático por el momento ha respaldado con mayor vigorosidad los acuerdos multilaterales transmitiendo confianza a la comunidad internacional.

\section{Ilustración 1}

\section{Confianza en el presidente Donald Trump para hacer lo correcto en relación con los asuntos internacionales}

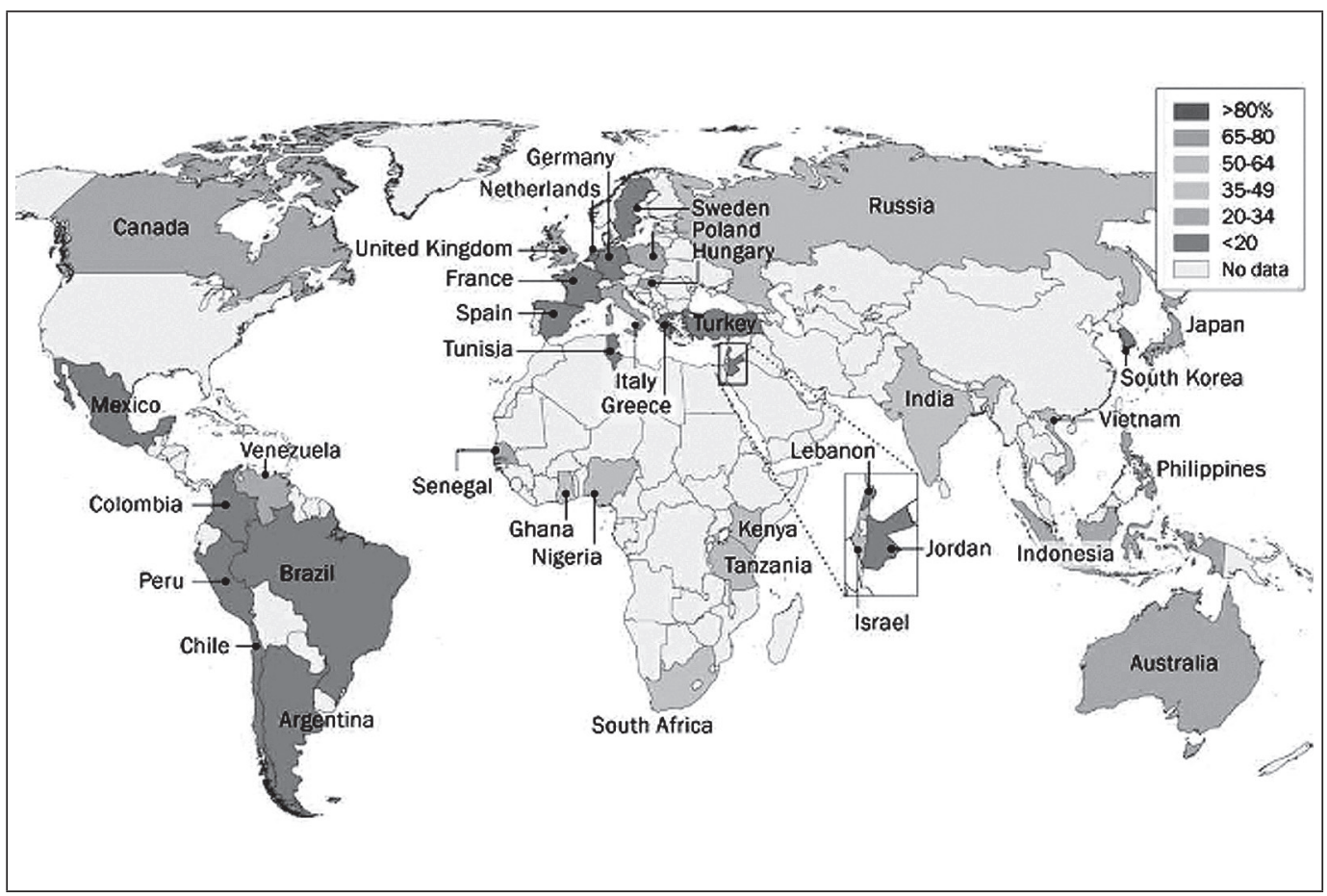

Fuente: Wike, R.; Stokes, B. \& Fetterolf, J. (2017). 


\section{CONCLUSIONES PRELIMINARES}

En la actualidad el nacional-populismo ha tomado fuerza política en Estados Unidos y en Europa. Para explicar este fenómeno, sus causas y consecuencias en el siglo xxI, fue necesario ceñirse a la teoría de estos dos conceptos y realizar una breve descripción sobre la presencia de esta manifestación en otros momentos de la historia de la sociedad. No obstante, se evidenció que el concepto nacionalismo tiene un amplio desarrollo conceptual, mientras que el populismo presenta problemas importantes desde su definición hasta su aplicación, permitiendo así que sea remplazado por intuiciones y rasgos característicos generales, y se convierta en un insulto en la democracia moderna para vetar el debate sobre el bienestar de las sociedades.

El nacional-populismo, como categoría de análisis político, es considerado un fenómeno epifenoménico de la democracia moderna, de ahí que su principal promotor de crecimiento sea el propio régimen político. Esta doctrina política, según la cual la soberanía reside en el pueblo, le ha prometido y creado esperanzas a los ciudadanos que a menudo incumple. Esta situación ha engendrado en el pueblo la sensación de estar desprotegido y traicionado por la democracia, a pesar que ese sistema político es para él. Sin embargo, los detractores del populismo hallan las causas de esta manifestación en la ignorancia y los pensamientos malsanos de sus dirigentes, evitando así debatir sobre los cambios estructurales en los ámbitos sociales y económicos, debido al modelo neoliberal y de la globalización.

Asimismo, en el desarrollo de este trabajo se evidenció que el problema del populismo reside en dos factores. Por un lado, el histórico con el desarrollo conceptual que elaboró la psicología de las masas sobre este término y, por el otro, el componente de la demagogia en los discursos de los candidatos, que los convierte en deshonestos. Este es el caso del presidente electo de Estados Unidos, Donald Trump, quien a través de su discurso canalizó la rabia de los ciudadanos prometiendo beneficios para los trabajadores y clase media, pero que durante su administración ha tomado medidas que favorecen más a las grandes corporaciones y al sistema financiero que a los electores. Estas determinaciones tomadas por el republicano también han involucrado aspectos internacionales, las cuales se han caracterizado por su unilateralidad, el desdén y arrogancia del mandatario hacia los aliados de Washington.

Esta situación ha traído consigo consecuencias al liderazgo de los Estados Unidos y al orden internacional, pues aumenta el declive relativo del gigante norteamericano, debilita el actual orden mundial liberal y la agenda internacional establecida es poco clara para afrontar los temas de importancia.

En suma, el resurgimiento del nacionalpopulismo a causa de los déficits de la democracia y los elementos económicos y políticos explicados durante este trabajo, permiten formular algunas preguntas para seguir explorando en otros artículos: ¿los actuales líderes nacional-populistas serán capaces de medir las consecuencias de sus estrategias y acciones unilaterales?; ¡los líderes mundiales estarán dispuestos a modificar el actual modelo político y económico que no tiene satisfecha a la ciudadanía y que los líderes populistas se sirven para canalizar la rabia?; de continuar el 
aislamiento de Estados Unidos y el fortalecimiento de China, ¿la transición del poder del primero hacia el segundo se hará de manera pacífica o violenta?; con el nacional-populismo ¿el mundo estará entrando en una nueva etapa de transformación del sistema internacional?

\section{REFERENCIAS}

Badie, B. (2016). Nous ne sommes plus seuls au monde. Un autre regard sur l' "ordre international». Paris: Francia, La Découverte.

Bellamy, J. \& Magdoff, F. (2009). La gran crisis financiera: causas y consecuencias. Madrid, España: Fondo de Cultura Económica.

Cornejo, R. \& Navarro, A. (2010). China y América Latina: recursos, mercados y poder global. Revista Nueva Sociedad, No. 228, 79-99.

Delannoi, G. (1994). Réflexions sur le nationalisme. Esprit, 198(1), 84-96.

Delarue, Q. (2016). Le pivot vers l'Asie. L'hégémonie américaine en jeu? Institut de Relations Internationales et Stratégiques, 4, 2-16.

Delsol, C. (2016). Populismos: una defensa de lo indefendible. Bogotá: Editorial Ariel.

Duprat, A. (2003). Du patriotisme aux nationalismes (1700-1848), France, Grande-Bretagne, Amérique du Nord, ss dir. Bernard Cottret. Annales Historiques de la Révolution Française, 333, 1-3.

European Parliamentary Research Service. (2017). Global Trends to 2035. Geo-politics and international power (603.263). doi: 10.2861/22464.

Gilpin, R. (1990). La economía politica de las relaciones internacionales. Buenos Aires: Argentina, Grupo Editor Latinoamericano.

Granados, O. (2010). Imperios y colonialismo, 18701914 ¿una era de globalización, geopolítica o nacionalismo económico? Revista de Relaciones Internacionales Estrategia y Seguridad, 5(1), 51-82.

Haass, R. (2018). Liberal World Order, R.I.P. Recuperado del sitio de internet de Project Syndicate: https:// www.project-syndicate.org/commentary/end-ofliberal-world-order-by-richard-n--haass-2018-03

Heinno, A.; Caccavello, G. \& Sandell, C. (2017). Authoritarian Populism Index 2017. Recuperado del sitio de internet de European Policy Information center: http://www.epicenternetwork.eu/wp-content/uploads/2017/07/TIMBRO-AuthoritarianPopulism-Index-2017-Briefing.pdf

Hermet, G. (2003). El populismo como concepto. Revista de Ciencia Politica, 23(1), 5-18.

Hermet, G. (1992). Le retour du nationalisme. Revue Française de Science Politique, 42(6), 1042-1047.

Hobsbawn, E. (1991). Naciones y nacionalismos desde 1780. Barcelona: Crítica.

Kennedy, P. (1989). Auge y caida de las grandes potencias. Barcelona: Plaza \& Janés Editores.

Kissinger, H. (2016). Orden mundial. Reflexiones sobre el carácter de los países y el curso de la historia. Bogotá: Penguin Random House Grupo Editorial.

Laclau, E. (2005). La razón populista. Bogotá: Colombia, Fondo de Cultura Económica.

Landes, H. (2016). Allô Houston! Paris: Max Milo.

La República. (05/02/2018). China rechaza críticas de EE.UU. sobre relaciones con Venezuela. Recuperado de: https://www.larepublica.co/ globoeconomia/china-rechaza-criticas-de-eeuusobre-relaciones-con-venezuela-2596247

Lissardy, G. (02/02/2018). "América Latina no necesita un nuevo poder imperial": la dura advertencia de Estados Unidos sobre la creciente influencia de China en la región. BBC Mundo. Recuperado de: http://www.bbc.com/mundo/noticiasinternacional-42913719 
Márquez, M. (2011). Perspectivas teóricas para abordar la nación y el nacionalismo. Pap.polit., 16(2), $567-595$.

Ochoa, L. \& Prado, J. (2017). Cosmopolitismo, constructivismo y liberalismo institucional: diálogo teórico en torno a la cooperación internacional para el desarrollo. Revista Iberoamericana de Filosofía, Politica y Humanidades, (37), 273-299. doi: 10.12795/araucaria. 2017.i37.14.

Patiño, C. (2017). Imperios contra Estados. La destrucción del orden internacional contemporáneo. Bogotá: Penguin Random House Grupo Editorial.

Política Exterior. (2011). Segunda potencia económica del mundo. Recuperado de: https://www.politicaexterior.com/articulos/economia-exterior/segundapotencia-economica-del-mundo/

Sepúlveda, I. (1996). La investigación del nacionalismo: evolución, temas y metodología. Espacio, Tiempo y Forma. Serie V, Historia Contemporánea, 9, 315-336.
Sodupe, K. (2002). La estructura de poder del sistema internacional: del final de la segunda guerra mundial a la posguerra fría. Madrid: Fundamentos.

Spruyt, B. (2016). Who supports Populism and What attracts people do it? Political Research Quarterly, 69(2), 335-346. doi: 10.1177/106591291663 9138.

Statista. (2018). U.S. household income distribution from 1990 to 2016 (by Gini-coefficient). Recuperado del sitio de internet de The Statista Portal: https://www.statista.com/statistics/219643/ gini-coefficient-for-us-individuals-families-andhouseholds/

Villamizar, F. (2011). El soft power chino. Un acercamiento. Revista Enfoques, 9(14), 75-88.

Wike, R.; Stokes, B. \& Fetterolf, J. (2017). Worldwide, few confident in Trump or his policies. Recuperado del sitio de internet de Pew Research Center: http:/www.pewglobal.org/2017/06/26/worldwide-few-confident-in-trump-or-his-policies/ 